The Malaysian

Journal of Social Administration, 9 (1): 35-58

\title{
PENGGUNAAN INDIKATOR PERATURAN KELAYAKAN BERASAS PENDAPATAN DAN PELUANG KANAK- KANAK MENDAPAT BANTUAN SOSIAL AWAM
}

\section{Normila Ilias, M.A (Pentadbiran Sosial)}

Felo akademik, Jabatan Sains Sosial, Fakulti Pengajian Kontemporari

Islam, Universiti Sultan ZainalAbidin, 21300 Kuala Terengganu,

Terengganu, Malaysia. Normila83@gmail.com

\section{Siti Hajar Abu Bakar Ah, PhD}

Profesor Madya, JabatanPentadbiran dan KeadilanSosial, Universiti Malaya. shajar@um.edu.my

\section{Abd. Hadi Zakaria, PhD \\ Profesor, Jabatan Sains Sosial, Fakulti Pengajian Kontemporari Islam, Universiti Sultan ZainalAbidin, 21300 Kuala Terengganu, Terengganu, Malaysia. abdhadi@unisza.edu.my}

Well-being of a child is closely related to the socio-economic status of his/her household. Economic deprivation of one's household not only contributes to child poverty; but also have some bearing on the child's likelihood to be considered as an eligible public social assistance recipient. A survey was carried out in 2007 to examine the ways in which socio-economic statuses of households impinged on a child's opportunity to receive social assistance. A total of 230 children, who were listed in the application list of Child Benefits Scheme administered by the Social Welfare Department in Pasir Puteh District, Kelantan were involved in the study. The findings show that there is a significant relationship ( $p>.000)$ between the socio-economic characteristics and a child's likelihood to be eligible for social assistance. The findings also indicate that eligibility rules which are based on income (means test) are pertinent in the selection of eligible public social assistance recipients.

Kata kunci: Peraturan kelayakan, bantuan sosial awam, kanak-kanak miskin 


\section{PENGENALAN}

Kebelakangan ini pelbagai isu sering diperkatakan di media-media massa dan elektronik berkaitan dengan syarat-syarat peraturan kelayakan dalam pemberian bantuan sosial awam. Antara isu yang hangat menjadi perbualan ialah bantuan yang diberikan oleh Jabatan Kebajikan Masyarakat (JKM) tidak mencukupi, prosedur memohon bantuan rumit dan ramai pemohon yang layak tercicir daripada senarai bantuan. Ketiga-tiga isu tersebut sedikit sebanyak menggambarkan kelemahan atau fragmentasi dalam sistem peraturan kelayakan sedia ada.

\section{PERATURAN KELAYAKAN}

Peraturan kelayakan (eligibility rules), menurut Gilbert dan Terrell (1998) adalah sekumpulan syarat, keadaan, ciri atau situasi prasyarat serta manfaat sosial kepada seseorang individu atau sesebuah kumpulan sosial dan komuniti tertentu. Perkara ini merujuk kepada keadaan atau ciri-ciri yang telah ditetapkan dan perlu ada pada seseorang pemohon dan kumpulan sosial bagi melayakkan individu dan kumpulan sosial berkenaan diberi bantuan awam. Syarat kelayakan bagi Bantuan Orang Tua (BOT) contohnya ialah individu yang berusia 65 tahun ke atas dan miskin. Jika seorang individu berusia memenuhi kedua-dua ciri utama yang telah ditetapkan ini maka beliau telah berkelayakan untuk memohon bantuan awam ini.

Chambers (2000) menyatakan peraturan kelayakan digunakan bagi menentukan empat perkara. Pertama, siapa yang layak dan patut menerima bantuan. Kedua, berapa banyak manfaat bantuan yang diberi dan diperolehi. Ketiga, sampai bila bantuan akan diberikan. Keempat, apakah syarat-syarat dan kelayakan yang melayakkan seseorang itu untuk mendapatkan bantuan tersebut.

Peraturan kelayakan dalam pemberian bantuan sosial awam boleh dikhususkan kepada empat jenis utama; iaitu peraturan kelayakan berasaskan keperluan ciri semulajadi, peraturan kelayakan bersasaskan tahap kerugian, peraturan kelayakan berasaskan perbezaan diagnosis dan peraturan kelayakan berasaskan keupayaan pendapatan (Siti Hajar, 2007; Gilbert dan Terrel, 1998; Gilbert dan Specht, 1974).

\section{Ujian keperluan ciri semula jadi}

Kelayakan individu mengikut ciri semulajadi adalah berdasarkan kepada ciri-ciri tabie yang dimiliki oleh individu berkenaan (Siti Hajar, 2007). Ciri- 
ciri semulajadi individu ditentukan oleh budaya, nilai dan norma sosial yang dianggotai atau yang melingkari kehidupan individu. Lazimnya, individu atau kumpulan masyarakat yang tergolong dalam kumpulan sosial yang sama mempunyai keperluan yang sama. Maka itu, perkhidmatan atau bantuan sosial yang sama disediakan untuk kumpulan sosial yang sama.

Kami ingin memetik beberapa program sosial yang diberikan berdasarkan ujian keperluan semula jadi. Program Makanan Tengahari Nasional atau National School Lunch Program (NSLP) di Amerika Syarikat menyediakan makanan yang berkhasiat kepada kanak-kanak miskin yang belajar di sekolah. Tujuannya ialah supaya kanak-kanak tersebut mendapat khasiat makanan yang seimbang bagi membantu tumbesaran dan perkembangan minda mereka dengan baik. Syarat kelayakan utama program ini ialah kanak-kanak mesti datang dari keluarga yang berpendapatan rendah. Kanak-kanak tersebut diberi makanan percuma tiap-tiap hari di sekolah semasa waktu makan tengah hari ( Pecora et al., 2000).

Program Wanita, Bayi dan Kanak-Kanak (Women, Infant and Children Program) di Amerika Syarikat juga menggunakan ujian kelayakan ini. Program ini memberi tumpuan sepenuhnya terhadap ibu mengandung kerana kerajaan Amerika Syarikat percaya yang nutrisi kanak-kanak bermula dalam kandungan ibu. Justeru, tindakan memenuhi keperluan nutrisi kaum wanita yang hamil secara eksplisitnya melambangkan tanggungjawab memenuhi keperluan asasi seorang kanak-kanak. Secara implisitnya pula, program ini menggambarkan komitmen negara dalam memastikan kaum wanitanya melahirkan generasi yang sihat. Wanita mengandung yang berpendapatan pada garis kemiskinan atau di bawah garis kemiskinan dan menghadapi masalah nutrisi layak menerima atau menyertai program ini. Bantuan makanan berkhasiat diberikan sepanjang tempoh seseorang wanita itu mengandung atau sehingga kanak-kanak tersebut mencapai umur 5 tahun; bergantung kepada tahap kemiskinan ibu dan kesihatan anak.

Keperluan ciri semulajadi dijelaskan mengikut ukuran piawaian normatif. Keperluan normatif merujuk kepada keperluan yang telah ditetapkan oleh anggota masyarakat menerusi sekumpulan ukuran sosial yang seragam. Ukuran yang seragam ini ditentukan dan dibina oleh profesional atau pakar sesebuah perkhidmatan. Justeru, individu yang menepati ukuran tersebut dilihat sebagai berkeperluan dan berhak mendapat perkhidmatan sosial yang disediakan. Sebaliknya, individu yang tidak menepati ukuran tersebut dilihat sebagai tidak berkeperluan dan tidak berhak memperoleh perkhidmatan sosial yang ada (Siti Hajar, 2006). 
Strategi kebajikan sosial yang paling sesuai untuk agihan kebajikan sosial mengikut prinsip ini ialah peruntukan secara berkumpulan; iaitu perlindungan sosial yang berasaskan kriteria normatif yang seragam. Contohnya program sosial untuk meningkatkan nutrisi kaum wanita, kanakkanak dan bayi harus meliputi semua wanita mengandung, wanita yang menyusukan anak, kanak-kanak dan bayi yang berisiko tinggi kepada masalah kekurangan nutrisi (Siti Hajar, 2007; Gilbert dan Terell, 1998).

\section{Ujian tahap ganti rugi}

Gantirugi atau pampasan merujuk kepada wang atau barangan yang dibayar secara gantirugi (Dewan Bahasa dan Pustaka, 2005). Prinsip ini mensyaratkan individu menganggotai satu kumpulan sosial yang menyumbang atau mencarum kepada badan-badan perlindungan sosial khusus (Siti Hajar, 2007; Gilbert dan Terrell, 1998). Ujian kelayakan gantirugi merupakan komponen utama dalam kebanyakan skim atau program perlindungan sosial.

Thompson (1995) menyatakan ujian kelayakan gantirugi menjadi asas kepada pembentukan dan perkembangan sistem dan institusi kebajikan di kebanyakan negara; baik di Barat mahupun di Timur. Mengikut ujian kelayakan ini, kelayakan individu menerima bantuan ditentukan oleh rekod caruman atau sumbangan yang telah dibuat. Ini bermakna kelayakan individu untuk menerima manfaat skim perlindungan sosial adalah tertakluk kepada sumbangan atau caruman atau simpanan semasa dan masa lalu yang telah dibuat oleh pekerja dan majikan (Siti Hajar, 2007; Gilbert dan Terrell, 1998).

Indikator utama prinsip ini dalam menyediakan bantuan, mengagihkan bantuan dan perkhidmatan sosial awam kepada masyarakat ialah dengan menggunakan strategi yang berorientasikan kumpulan yang terfokus kepada prinsip kolektif (Siti Hajar, 2007; Gilbert dan Terrell, 1998; Gilbert dan Specht, 1974). Di Malaysia, antara contoh program yang mengikut ujian kelayakan ini ialah skim-skim manfaat pekerjaan yang terdapat di dalam Kumpulan Wang Simpanan Pekerja, skim-skim Keselamatan Sosial Pekerja seperti Elaun Kecacatan Kekal dan Sementara, Pencen Ilat, Manfaat Kematian dan Pampasan Kemalangan Pekerjaan, skimskim persaraan awam dan skim-skim pencen awam.

Kami ingin memetik Skim Pampasan Pekerjaan di Negara Jerman sebagai contoh program skim awam yang beroperasi di atas ujian kelayakan ini. Program Insurans Anak Tanggungan Pekerja (Survivors Insurance) ini telah ditubuhkan sejak tahun 1939. Program insurans ini memberi manfaat 
kepada anak-anak pencarum (pekerja) setelah pekerja tersebut meninggal dunia. Kelayakan untuk mendapat bantuan ini ialah pencarum; iaitu bapa kepada kanak-kanak tersebut telah meninggal dunia dan kanak-kanak berkenaan berumur di bawah 18 tahun. Kadar bantuan yang diberikan kepada kanak-kanak bergantung kepada jumlah pendapatan pencarum semasa bekerja. Bantuan diberikan secara bulanan dalam bentuk kewangan. Purata kadar bantuan bulanan adalah sebanyak USD 487 (Pecora et al., 2000).

Kerajaan Malaysia, dalam Skim Kumpulan Wang Simpanan Pekerja (KWSP) nya juga mengamalkan ukuran kelayakan ini. Pencarum hanya layak mendapat manfaat sekiranya mencapai umur persaraan 50 tahun. Manfaat yang disediakan oleh KWSP ialah faedah persaraan, dividen, bantuan hilang keupayaan, bantuan kematian dan pelepasan cukai pendapatan. Ia merupakan perkhidmatan perlindungan sosial yang menjamin masa depan pekerja dan keluarga mereka (Siti Hajar, 2007).

\section{Ujian perbezaan diagnosis}

Menurut Dewan Bahasa dan Pustaka (2005), perkataan "diagnosis" merujuk kepada perbuatan mengenal pasti sesuatu penyakit daripada tanda dan gejalanya (hal.348). "Diagnosis" lazimnya melibatkan penilaian profesional terhadap kes individu (Siti Hajar, 2007). Kelayakan pemohon bantuan yang menggunakan asas kelayakan ini adalah bergantung kepada penilaian seorang atau sekumpulan pakar atau profesional seperti doktor, pakar psikologi, kaunselor, pekerja sosial kanak-kanak terhadap keadaan-keadaan khusus individu yang mengalami kecacatan fizikal, keuzuran dan gangguan emosi (Chambers, 2000; Gilbert dan Terrell, 1998; Gilbert dan Specht, 1974). Pemohon bantuan di bawah ujian kelayakan ini disyaratkan supaya membuat satu siri ujian pemeriksaan kesihatan di hospital yang disarankan; selalunya hospital awam. Ia bertujuan untuk mengesahkan keadaan kesihatan pemohon.

Ukuran kelayakan ini boleh dilihat dalam kebanyakan skim-skim bantuan sosial awam untuk golongan OKU. Jika laporan kesihatan yang dikeluarkan oleh Pegawai Perubatan/Pakar Perubatan Kerajaan atau Pakar Perubatan Swasta mengesahkan bahawa pemohon bantuan mengalami mana-mana daripada 7 keuzuran dalam kategori ketidakupayaan dan kefungsiannya seperti kurang upaya pendengaran, kurang upaya penglihatan, kurang upaya pertuturan, kurang upaya fizikal, masalah pembelajaran dan kurang upaya mental, maka pemohon layak untuk diberi bantuan sosial seperti Bantuan Kanak-kanak (BKK), Bantuan Alat Tiruan/Alat Sokongan 
dan Elaun Pekerja Cacat. Jenis bantuan diberikan berdasarkan ketidakupayaan dan ketidakfungsian individu yang didiagnosis dan disahkan oleh pakar perubatan. Kebanyakan skim sosial awam yang bersifat pampasan gantirugi juga menggunakan ujian kelayakan ini. Contohnya, Skim Pampasan Pekerjaan atau PERKESO dan Elaun Kecacatan Kekal (Permanent Disability Benefits).

\section{Ujian keupayaan tahap pendapatan}

Menurut Dewan Bahasa dan Pustaka (2005), pendapatan merupakan jumlah wang yang diperoleh dalam jangka waktu tertentu seperti hasil daripada mata pencarian dan kerja yang dilakukan. Mengikut prinsip ini kelayakan individu menerima bantuan ditentukan oleh tahap pendapatan yang diperolehinya.

Mengikut piawaian kemiskinan di Malaysia, keluarga yang berpendapatan di bawah Paras Garis Kemiskinan (PGK) layak untuk membuat permohonan bagi mendapatkan bantuan di bawah ujian keupayaan pendapatan ini. Piawaian tahap pendapatan tersebut mempengaruhi peraturan kelayakan yang berasaskan pendapatan kerana matlamat bantuan adalah untuk mensasarkan golongan keluarga atau individu yang berpendapatan rendah dan miskin. Indikator utama yang dijadikan panduan dalam peraturan kelayakan berasaskan tahap pendapatan adalah keperluan ekonomi individu dan/atau isi rumahnya. Indikator ini menggunakan kesulitan individu dalam memenuhi keperluan asasi keluarganya sebagai asas kelayakan diberi bantuan.

Contoh program dan bantuan yang diagihkan mengikut peraturan kelayakan ini ialah Program Aid to Families With Dependent Children (AFDC), Temporary Assistance For Needy families (TANF) dan Program Kebajikan-pekerjaan (Workfare Programs) di Amerika Syarikat, serta Program Pembangunan Rakyat Termiskin, Program Meningkatkan Pendapatan, Bantuan Kanak-Kanak, Bantuan Anak Pelihara, Bantuan Sekolah dan Geran Pelancaran di Malaysia. Program Aid to Families with Dependent Children (AFDC) misalnya merupakan bantuan kewangan bulanan yang diberikan kepada keluarga untuk membantu menjaga kesejahteraan anak-anak mereka. Antara syarat kelayakan bagi mendapatkan bantuan ini adalah pendapatan keluarga berada di bawah garis kemiskinan, keluarga tunggal dan mempunyai anak-anak yang berumur di bawah 18 tahun. Kadar bantuan adalah bergantung kepada kawasan tempat tinggal sesebuah keluarga serta jumlah tanggungan keluarga tersebut. Jika sebuah keluarga tunggal tinggal di kawasan bandar dan mempunyai empat orang 
ahli seperti ibu dan tiga orang anak, kerajaan akan memberikan bantuan bulanan sebanyak USD950. Sebaliknya, jika keluarga tunggal tersebut tinggal di kawasan luar bandar maka kadar bantuan bulanan yang akan diterima adalah sebanyak USD 250 (Pecora et al., 2000).

Program Temporary Assistance For Needy families atau TANF pula adalah bantuan jangka panjang yang membantu kanak-kanak semasa di alam pekerjaan mereka nanti. Antara kelayakan bantuan di bawah program ini ialah pendapatan keluarga pemohon berada dibawah paras garis kemiskinan, pemohon berumur di bawah 18 tahun, tidak berkahwin, tinggal bersama keluarga dan masih belajar. Bantuan ini boleh diterima setelah mereka memasuki alam pekerjaan dan bekerja selama dua tahun. Contoh faedah maksimum yang di perolehi untuk sesebuah keluarga di Mississippi ialah USD120 dan di Aslaka USD923 (Alexandrova dan Grishina, 2007; Commitee on Ways and Means, 1998).

\section{METODOLOGI}

Satu kajian lapangan telah dilakukanbertujuan untuk mengenal pasti ciri-ciri sosio-ekonomi isi rumah kanak-kanak yang mempengaruhi peluang kanakkanak dalam menerima bantuan. Kajian ini telah dilakukan di sekitar kawasan pentadbiran Pejabat Kebajikan Masyarakat, Jajahan Pasir Puteh, Kelantan. Kajian ini telah menggunakan teknik persampelan bertujuan (purposive sampling) bagi memilih lokasi dan/atau organisasi kajian. Jabatan Kebajikan Masyarakat, Pasir Puteh, Kelantan dipilih sebagai organisasi kajian kerana faktor masa, kewangan, kemudahan dan kesesuaian organisasi dengan tajuk kajian. Organisasi ini mengurus-tadbir pemberian Skim Bantuan Kanak-Kanak (BKK) bagi seluruh jajahan Pasir Puteh. Syarat kelayakan pemberian bantuan BKK yang digunakan adalah seragam di seluruh negeri di Malaysia. Teknik persampelan mudah (convenience sampling) pula digunakan bagi memilih responden yang tersenarai dalam buku permohonan bantuan BKK di pejabat tersebut sebagai responden kajian ini.

Unit analisis kajian ini ialah isi rumah; bukannya keluarga. Sebanyak 230 buah isi rumah kanak-kanak yang memohon BKK di Pejabat Kebajikan Masyarakat Jajahan Pasir Puteh Kelantan telah dipilih sebagai responden kajian. Isi rumah kanak-kanak ini dikategorikan kepada dua kumpulan. Kumpulan A terdiri daripada 180 buah isi rumah kanak-kanak yang permohonan bantuan mereka diluluskan; iaitu penerima bantuan BKK. Kumpulan B pula terdiri daripada 50 buah isi rumah kanak-kanak yang bantuan mereka tidak diluluskan; iaitu bukan penerima BKK. 
Pengumpulan data primer kajian telah dibuat dengan menggunakan tiga teknik utama. Pertama, temubual berstruktur yang menggunakan borang soal selidik berstruktur. Borang soal selidik telah dibina berasaskan kajian Alexandrova dan Grishina (2007) yang bertajuk "Who receives target in transition? The effect of household characteristics on take up rates in Russia's child allowance program". Kedua, temubual separa berstruktur yang dilakukan menggunakan borang panduan temubual separa berstruktur ke atas beberapa orang pegawai dan kakitangan JKM. Data kualitatif yang diperolehi daripada temubual dengan pemberi maklumat utama ini digunakan bagi mengukuhkan lagi maklumat yang telah sedia ada. Ketiga, maklumat sekunder telah diperolehi melalui dokumen dan fail-fail bantuan di JKM, jurnal, akhbar, buku dan halaman jaring. Data-data terkumpul telah dianalisis secara deskriptif dengan menggunakan perisian Statistical Package For The Social Sciences (SPSS). Data yang telah dianalisis dibentang dalam bentuk jadual, peratusan dan khi kuasa dua.

\section{DAPATAN KAJIAN}

Bantuan Kanak-Kanak (BKK) ialah bantuan kewangan bersifat sementara untuk kanak-kanak miskin. Bagi memastikan skim berjaya disampaikan kepada kanak-kanak miskin, kemiskinan pemohon menjadi ciri ukuran utama bantuan ini. Kemiskinan isi rumah diukur dengan menggunakan serangkaian ukuran ekonomi bagi memastikan pemohon benar-benar berada dalam kategori miskin.

Sekiranya kita menyorot perkembangan sistem kebajikan moden di kebanyakan negara; termasuk Malaysia, institusi dan sistem kebajikan sosial formal diwujudkan bagi bertindak-balas dengan masalah kemiskinan. Pemberian bantuan menggunakan ujian keupayaan pendapatan pula telah diamalkan sekian lama bagi mengukur kemiskinan dalam kalangan kumpulan berkeperluan yang layak diberi bantuan awam. Bagi konteks negara Malaysia, Pendapatan Garis Kemiskinan atau PGK merupakan ukuran utama yang digunakan untuk mengukur kemiskinan. Mengikut PGK yang dikeluarkan oleh Laporan Penyiasatan Isi rumah atau HIS oleh Jabatan Perangkaan Malaysia pada tahun 2007 dan 2009, golongan miskin ialah golongan yang mempunyai pendapatan kurang dari RM720 bagi Semenanjung, RM960 bagi Sabah dan RM830 bagi Sarawak. Miskin tegar pula ialah golongan yang mempunyai pendapatan kurang dari RM430 bagi Semenanjung Malaysia, RM540 bagi Sabah dan RM520 Sarawak. Nilai PGK ini menjadi panduan kelayakan pendapatan utama dalam pemilihan pemohon BKK yang layak. 
Secara keseluruhannya, kajian ini mendapati indikator ekonomi masih menjadi teras utama peraturan kelayakan BKK. Semakin miskin keadaan ekonomi isi rumah, semakin tinggi peluang pemohon dari isi rumah berkenaan untuk menerima bantuan sosial awam yang dipohon. Terdapat beberapa indikator ekonomi isirumah yang digunapakai oleh pihak JKM bagi mengukur kelayakan pemohon menerima bantuan BKK. Indikatorindikator ini adalah status pekerjaan ketua isi rumah, pendapatan bulanan isi rumah, pemilikan aset tetap isi rumah dan perbelanjaan bulanan isi rumah.

\section{Status pekerjaan ketua isi rumah}

Pekerjaan ketua isi rumah kanak-kanak menggambarkan kestabilan dan kekukuhan ekonomi sesebuah isi rumah. Ekonomi sesebuah isi rumah kukuh sekiranya ketua isi rumah mempunyai pekerjaan tetap. Ini kerana pendapatan yang diperolehi daripada pekerjaan merupakan sumber kewangan utama untuk kebanyakan keluarga menguruskan keperluan asasi keluarga. Isi rumah yang terganggu sumber ekonomi bulanannya berisiko tinggi untuk berada dalam kemiskinan. Ketua isi rumah yang mempunyai pekerjaan yang stabil dan menjamin masa depan lazimnya hidup dalam keadaan sejahtera.

Kajian ini mendapati sebilangan besar kanak-kanak yang diberi bantuan BKK adalah terdiri daripada kanak-kanak yang datang dari isirumah yang ketuanya tidak bekerja. Kajian mendalam yang dilakukan ke atas failfail permohonan mereka ini memperlihatkan kebanyakannya terdiri daripada golongan berusia yang tidak berupaya untuk bekerja lagi, serta ibu tunggal yang tiada pekerjaan. Bagi ketua isi rumah yang berusia, mereka tiada kudrat untuk bekerja kuat lagi. Jika bekerja pun, hanya sekadar bercucuk tanam sayur-sayuran di belakang rumah untuk keperluan harian sahaja.

Dalam kalangan ibu tunggal yang tidak bekerja pula, ramai daripada mereka terhalang untuk keluar bekerja kerana perlu menjaga anak-anak yang masih kecil dan ramai. Kemiskinan yang dialami menyebabkan ibu tunggal ini tidak mampu untuk mengupah pengasuh menjaga anak-anak. 
Jadual 1: Status Pekerjaan Ketua Isi Rumah dan Peluang Kanak-kanak Menerima BKK

\begin{tabular}{|c|c|c|c|c|c|c|}
\hline \multirow{3}{*}{$\begin{array}{l}\text { Pekerjaan Ketua Isi } \\
\text { Rumah }\end{array}$} & \multicolumn{4}{|c|}{ Isi Rumah Kanak-Kanak } & \multirow{3}{*}{$x^{2}$} & \multirow{3}{*}{$\mathbf{p}$} \\
\hline & \multicolumn{2}{|c|}{$\begin{array}{l}\text { Penerima } \\
\text { Bantuan }\end{array}$} & \multicolumn{2}{|c|}{$\begin{array}{c}\text { Bukan } \\
\text { Penerima } \\
\text { Bantuan }\end{array}$} & & \\
\hline & $\begin{array}{c}\text { Bil. } \\
\text { (Isi } \\
\text { rumah } \\
\text { ) }\end{array}$ & $\%$ & $\begin{array}{c}\text { Bil. } \\
\text { (Isi } \\
\text { rumah } \\
\text { ) }\end{array}$ & $\%$ & & \\
\hline Tidak Bekerja & 85 & 47.5 & - & - & & \\
\hline Bekerja Sendiri & 2 & 1.1 & - & - & & \\
\hline Buruh Am & 42 & 22.9 & 2 & 4 & & \\
\hline Berniaga & 19 & 10.6 & 21 & 42 & & \\
\hline $\begin{array}{l}\text { Petani, Nelayan dan } \\
\text { Penoreh Getah }\end{array}$ & 31 & 17.3 & 9 & 18 & & \\
\hline $\begin{array}{l}\text { Perkhidmatan Awam } \\
\text { (seperti Polis, Tentera, } \\
\text { Bomba) }\end{array}$ & - & - & 3 & 6 & 113.807 & .000 \\
\hline Perkeranian dan Teknik & 1 & 0.6 & 10 & 20 & & \\
\hline Pencen & - & - & 5 & 10 & & \\
\hline Jumlah & 180 & 100.0 & 50 & 100.0 & & \\
\hline
\end{tabular}

$\mathrm{p} \leq .05 ; \mathrm{N}=230$

Maklumat dalam Jadual 1 menunjukkan hubungan di antara jenis pekerjaan ketua isirumah dengan peluang pemohon menerima bantuan. Kajian ini mendapati bahawa rata-rata isi rumah yang diberi bantuan adalah isi rumah yang terlibat dalam pekerjaan yang berpendapatan rendah dan tidak stabil seperti perburuhan am, petani, nelayan dan penoreh getah. Pendapatan bagi jenis-jenis pekerjaan ini adalah amat rendah; lazimnya berada di bawah paras PGK. Walaupun terdapat 10.6 peratus penerima BKK datang daripada isi rumah yang ketua keluarganya berniaga, mereka hanya melakukan perniagaan kecil-kecilan seperti menjual kuih, lauk pauk, menjaja ais krim dan sate ikan yang berpendapatan tidak menentu dan hanya untuk secukup hidup sahaja. 
Perkara penting yang perlu diberi perhatian berkaitan dengan indikator ini adalah kajian ini mendapati terdapat perbezaan yang signifikan $(\mathrm{p}<.000)$ antara status pekerjaan ketua isi rumah kanak-kanak dengan peluang kanak-kanak diberi atau tidak diberi bantuan kewangan awam. Justeru, status pekerjaan ketua isi rumah; iaitu bekerja atau tidak bekerja, serta jenis pekerjaan yang dilakukan perlu dikekalkan oleh pihak JKM sebagai salah satu kayu pengukur kelayakan pemohon diberi bantuan atau tidak. Cuma, mungkin pihak JKM perlu meneliti dengan lebih mendalam punca-punca yang menyebabkan ketua isi rumah tidak bekerja dan terlibat hanya dalam jenis pekerjaan yang berpendapatan rendah. Ini penting bagi mengelakkan JKM terlepas pandang kepada ketua isi rumah yang sihat fizikal dan mentalnya dan berupaya untuk bekerja, tetapi malas berusaha.

\section{Pendapatan bulanan isi rumah}

Kesejahteraan sesebuah isi rumah boleh ditentukan berdasarkan kepada pendapatan bulanan isi rumah secara keseluruhan. Pendapatan isi rumah terdiri daripada pendapatan tetap bulanan dan pendapatan tidak langsung. Pendapatan tetap di sini merujuk kepada jumlah upah/bayaran yang diterima hasil daripada pekerjaan tetap isi rumah. Manakala, pendapatan tidak langsung pula adalah upah/bayaran yang diterima daripada pekerjaan sampingan isi rumah. Pendapatan bulanan sebuah isirumah merangkumi pendapatan tetap daripada pekerjaan yang dilakukan oleh ketua isi rumah seperti berniaga, buruh, petani, nelayan dan penoreh getah, serta pendapatan ahli-ahli lain isi rumah seperti pendapatan isteri dan anak-anak yang bekerja serta upah kerja lebih masa ketua isi rumah.

Jadual 2 memaparkan pendapatan bulanan isirumah kanak-kanak yang memohon BKK. Hampir semua pemohon BKK yang layak diberi bantuan adalah terdiri daripada isi rumah miskin yang berpendapatan kurang RM720 dan miskin tegar yang berpendapatan kurang RM430. Malah, lebih daripada 66.1 peratus adalah terdiri daripada isi rumah yang dikategorikan sebagai miskin tegar. Terdapat 27 orang pemohon yang berada dalam kategori pendapatan kurang RM100 hingga kurang RM700, tetapi ditolak permohonannya. Mereka ini telah tidak diberi bantuan kerana berdasarkan fail JKM tanggungan isi rumah mereka tidak ramai, ada anak yang sudah bekerja dan/atau ketua isi rumah ada pendapatan sampingan hasil dari kerja lebih masa. Secara keseluruhannya, hasil kajian ini mendapati bahawa kanak-kanak yang isi rumah mereka miskin tegar yang berpendapatan kurang RM430 berpeluang tinggi untuk mendapatkan bantuan; berbanding kanak-kanak isi rumah yang lain. Dapatan ini konsisten pendapat Townsend 
(1975) yang mengatakan pemberian bantuan berasakan pendapatan sangat cenderung untuk memfokus kepada golongan yang sara hidup mereka sangat miskin.

Jadual 2: Pendapatan Bulanan Isirumah dan Peluang Kanak-kanak Menerima BKK

\begin{tabular}{|c|c|c|c|c|c|c|}
\hline \multirow{3}{*}{$\begin{array}{c}\text { Pendapatan } \\
\text { bulanan } \\
\text { (RM) }\end{array}$} & \multicolumn{4}{|c|}{ Isirumah Kanak-Kanak } & \multirow{3}{*}{$x^{2}$} & \multirow{3}{*}{$\mathbf{p}$} \\
\hline & \multicolumn{2}{|c|}{ Penerima Bantuan } & \multicolumn{2}{|c|}{$\begin{array}{c}\text { Bukan Penerima } \\
\text { Bantuan }\end{array}$} & & \\
\hline & $\begin{array}{l}\begin{array}{l}\text { Bilangan } \\
\text { (Isirumah) }\end{array} \\
\end{array}$ & $\%$ & $\begin{array}{l}\text { Bilangan } \\
\text { (Isirumah) }\end{array}$ & $\%$ & & \\
\hline$\leq 100$ & 1 & 0.6 & 1 & 2.0 & \multirow{6}{*}{141.568} & \multirow{6}{*}{.000} \\
\hline $101-300$ & 119 & 66.1 & - & - & & \\
\hline $301-500$ & 41 & 22.8 & 2 & 4.0 & & \\
\hline $501-700$ & 15 & 8.3 & 24 & 48.0 & & \\
\hline $701-900$ & 4 & 2.2 & 23 & 46.0 & & \\
\hline Jumlah & 180 & 100.0 & 50 & 100.0 & & \\
\hline
\end{tabular}

$\mathrm{p} \leq .05 ; \mathrm{N}=230$

Sama seperti dapatan kajian mengenai status pekerjaan ketua isi rumah, kajian ini mendapati bahawa terdapat perbezaan yang signifikan $(\mathrm{p}<.000)$ di antara pendapatan bulanan isi rumah kanak-kanak dengan peluang mereka menerima atau tidak menerima BKK yang dipohon. Dapatan ini jelas sekali menunjukkan bahawa pendapatan isi rumah mempunyai pengaruh yang penting dalam menentukan kelayakan individu menerima atau tidak menerima bantuan sosial awam yang ada.

\section{Pemilikan aset tetap isi rumah}

Jenis pekerjaan, status pekerjaan dan tahap pendapatan isi rumah merupakan indikator klasik ekonomi yang lazim diambilkira dalam menilai kelayakan individu menerima bantuan sosial awam. Selain tiga indikator klasik ini, kajian ini juga mendapati bahawa pihak JKM mengambilkira aset tetap yang dimiliki oleh isi rumah yang menyumbang kepada pendapatan bulanannya. Pemilikan aset/harta merupakan item yang terdapat dalam Borang Penyiasatan JKM (17-pin.8/91/1). Tujuannya adalah untuk mengetahui segala aset/harta yang dimiliki oleh pemohon bantuan. Sekiranya pegawai 
JKM melalui siasatannya mendapati pemohon mempunyai aset/harta yang banyak, maka secara automatik permohonan bantuan mereka tidak akan diluluskan.

Titmuss (1962) merujuk aset tetap sebagai penyumbang kepada pendapatan bulanan. Titmuss mendesak agar pendapatan mengambil-kira semua bentuk pendapatan; sama ada sumbangan secara peribadi kepada individu mahupun aset berbentuk tetap, barangan dan bentuk tunai. Townsend (1975) juga mengatakan sumber isi rumah tidak terhad kepada pendapatan tunai sahaja. Ia perlu merangkumi pemilikan aset/harta tetap kepunyaan sendiri atau keluarga isi rumah. Friedman (1957) dan Johnson (1971) juga sependapat dengan Titmuss dan Townsend. Mereka berpendapat bahawa pendapatan bukan sahaja merangkumi satu sumber pendapatan tetap sahaja iaitu pekerjaan, tetapi pendapatan juga merangkumi pelbagai sumber yang mampu menyumbang kepada pendapatan. Dengan tegasnya mereka mengatakan yang pendapatan terdiri dari dua; iaitu pendapatan daripada perkhidmatan tenaga kerja dan pendapatan daripada aset tetap seperti duit tunai, akaun simpanan, bon-bon kerajaan, bon-bon korporat dan caruman perlindungan/sekuriti. Aset tetap ini boleh diklasifikasikan kepada dua bentuk; iaitu aset tahan lama dan aset tidak tahan lama. Lazimnya aset tahan lama seperti tanah, wang simpanan dan barang kemas mempunyai nilai yang tinggi. Manakala, nilai aset tidak tahan lama seperti haiwan ternakan dan kenderaan bermotor lebih cepat susut berbanding aset tahan lama. Secara kebiasaannya, isi rumah yang miskin ialah isi rumah yang tidak langsung mempunyai aset tetap tahan lama dan tidak mempunyai atau hanya mempunyai beberapa aset tidak tahan lama.

Data dalam Jadual 3 menunjukkan jenis-jenis aset/harta tetap yang dimiliki oleh isirumah kajian ini. Data dalam Jadual ini memperlihatkan bahawa berbanding dengan kumpulan kawalan, penerima BKK datang dari isi rumah yang tidak berharta. Dapatan kajian mendapati ada isi rumah pemohon bantuan yang memiliki aset tetap seperti tanah, wang simpanan, barang kemas, haiwan ternakan dan kenderaan bermotor contohnya kereta dan motosikal; yang boleh memberi pulangan pendapatan bulanan yang lumayan kepada pemiliknya. Justeru, dapatan kajian ini menggambarkan bahawa aset yang dimiliki isi rumah merupakan atribut yang boleh mendatangkan pendapatan sampingan kepada isi rumah dan atribut ini sememangnya perlu diberi penekanan kerana ia tergolong dalam aset tetap. 
Jadual 3: Pemilikan Aset/Harta Tetap Isirumah dan Peluang Kanak-kanak Menerima BKK

\begin{tabular}{|c|c|c|c|c|c|c|c|c|c|c|c|c|}
\hline \multirow{3}{*}{$\begin{array}{c}\text { Jenis-jenis } \\
\text { Aset }\end{array}$} & \multicolumn{8}{|c|}{ Isirumah kanak-kanak } & \multirow{2}{*}{\multicolumn{2}{|c|}{ Jumlah }} & \multirow{3}{*}{$X^{2}$} & \multirow{3}{*}{$\mathbf{P}$} \\
\hline & \multicolumn{4}{|c|}{ Penerima Bantuan } & \multicolumn{4}{|c|}{$\begin{array}{c}\text { Bukan Penerima } \\
\text { Bantuan }\end{array}$} & & & & \\
\hline & Ada & $\%$ & Tiada & $\%$ & Ada & $\%$ & Tiada & $\%$ & Bil & $\%$ & & \\
\hline Tanah & 39 & 17.0 & 141 & 61.0 & 39 & 17.0 & 11 & 5.0 & 230 & 100.0 & 55.407 & .000 \\
\hline $\begin{array}{l}\text { Wang } \\
\text { simpanan }\end{array}$ & - & - & 180 & 78.2 & 40 & 17.4 & 10 & 4.4 & 230 & 100.0 & 174.316 & .000 \\
\hline $\begin{array}{l}\text { Barang } \\
\text { kemas }\end{array}$ & 9 & 4.0 & 171 & 74.3 & 35 & 15.2 & 15 & 6.5 & 230 & 100.0 & 106.864 & .000 \\
\hline $\begin{array}{l}\text { Haiwan } \\
\text { ternakan }\end{array}$ & 10 & 4.3 & 170 & 74.0 & 40 & 17.4 & 10 & 4.3 & 230 & 100.0 & 127.465 & .000 \\
\hline $\begin{array}{l}\text { Kenderaan } \\
\text { bermotor }\end{array}$ & 53 & 23.0 & 127 & 55.0 & 43 & 19.0 & 7 & 3.0 & 230 & 100.0 & 51.469 & .000 \\
\hline
\end{tabular}

$\mathrm{p} \leq .05 ; \mathrm{N}=230$

Pendek kata, kajian ini mendapati bahawa pemilikan aset tetap isi rumah mempunyai hubungan yang amat signifikan dalam mempengaruhi peluang pemohon samada diberi atau tidak diberi bantuan sosial awam. Maka itu, indikator ini perlu diperluasi lagi oleh JKM kerana ia amat membantu dalam memilih mereka yang benar-benar layak diberi bantuan. Mereka yang tidak berpendapatan tetap tidak semestinya miskin sekiranya mereka mempunyai banyak aset tetap yang berfungsi sebagai pendapatan bulanan mereka. Selain itu, jenis-jenis aset tetap yang dimiliki isi rumah juga perlu diperluaskan lagi. Misalannya, syer saham, bunga yang diterima daripada simpanan tetap, sewa rumah, hasil perniagaan dan sebagainya mungkin boleh dimasukkan dalam kiraan ini.

\section{Perbelanjaan bulanan isi rumah}

Kadangkala pendapatan bulanan dan pekerjaan isi rumah tidak menggambarkan status sebenar ekonomi sesebuah isi rumah. Ini menyebabkan alternatif lain yang boleh digunakan untuk memberi gambaran sebenar keadaan ekonomi sesebuah isi rumah dicari. Salah satu daripada alternatifnya adalah menerusi perbelanjaan bulanan isi rumah.

Peningkatan kos sara hidup terutamanya harga barang keperluan harian yang semakin meningkat menyebabkan nilai pendapatan yang diterima menyusut. Pendapatan boleh lupus individu meningkat apabila harga barangan dan perkhidmatan naik dengan mendadak; sedangkan 
pendapatan berada pada tahap yang sama. Bebanan ini dirasai lebih kritikal oleh individu yang berpendapatan kecil. Hampir semua pendapatan yang diperolehi daripada pekerjaan mereka perlu digunakan untuk membeli barangan dan perkhidmatan keperluan harian keluarga; khususnya keperluan asasi.

Perbelanjaan isi rumah meliputi secara keseluruhan jumlah perbelanjaan bulanan yang dibelanjakan untuk hal-hal seperti makanan, pakaian, sewa rumah, kesihatan, persekolahan anak-anak, kesihatan, bil elektrik dan air. Asmah (1983, dalam Mohamed Zaini, 2010) menjelaskan bahawa peruntukan perbelanjaan golongan miskin berada dalam lingkungan 60-68 peratus daripada jumlah pendapatan mereka. Ini bermakna, golongan miskin lazimnya membelanjakan sebahagian besar pendapatan bulanan mereka untuk tujuan perbelanjaan keperluan asasi; bukannya untuk perbelanjaan barangan mewah dan perbelanjaan berekreasi.

Jadual 4: Perbelanjaan Bulanan Isirumah dan Peluang Kanak-kanak Menerima BKK

\begin{tabular}{|c|c|c|c|c|c|c|}
\hline \multirow{3}{*}{$\begin{array}{l}\text { Perbelanjaan } \\
\text { Bulanan } \\
(\mathbf{R M})\end{array}$} & \multicolumn{4}{|c|}{ Isirumah Kanak-Kanak } & \multirow{3}{*}{$X^{2}$} & \multirow{3}{*}{$\mathbf{p}$} \\
\hline & \multicolumn{2}{|c|}{$\begin{array}{c}\text { Penerima } \\
\text { Bantuan }\end{array}$} & \multicolumn{2}{|c|}{$\begin{array}{c}\text { Bukan Penerima } \\
\text { Bantuan }\end{array}$} & & \\
\hline & $\begin{array}{c}\text { Bilangan } \\
\text { (Isirumah) }\end{array}$ & $\%$ & $\begin{array}{c}\text { Bilangan } \\
\text { (Isirumah) }\end{array}$ & $\%$ & & \\
\hline$\leq 100$ & - & - & - & - & \multirow{6}{*}{60.617} & \multirow{6}{*}{.000} \\
\hline $101-300$ & 93 & 51.6 & - & - & & \\
\hline $301-500$ & 50 & 27.8 & 13 & 26.0 & & \\
\hline $501-700$ & 37 & 20.6 & 37 & 74.0 & & \\
\hline $701-900$ & - & - & - & - & & \\
\hline Jumlah & 180 & 100.0 & 50 & 100.0 & & \\
\hline
\end{tabular}

$\mathrm{p} \leq .05 ; \mathrm{N}=230$

Jadual 4 memaparkan jumlah perbelanjaan bulanan isi rumah kanak-kanak penerima bantuan dan isi rumah kanak-kanak bukan penerima bantuan. Kajian mendalam yang dilakukan oleh pengkaji ke atas fail-fail permohonan dan temubual dengan pegawai-pegawai JKM yang terlibat 
dalam pengurusan BKK mendapati bahawa pendapatan bulanan yang kecil mungkin menyumbang kepada perbelanjaan bulanan yang kecil. Ini kerana bagi isi rumah kanak-kanak yang berpendapatan rendah dan miskin mereka tidak mampu untuk berbelanja banyak kerana jumlah wang yang mereka ada adalah terhad. Maka itu, perbelanjaan mereka pun turut terhad juga. Mereka lebih menggunakan wang/pendapatan kepada perkara asas dalam memenuhi keperluan kehidupan harian seperti makanan, pakaian dan persekolahan anak-anak. Inilah yang menyebabkan majoriti besar pemohon yang layak diberi bantuan adalah terdiri daripada pemohon yang isi rumahnya berbelanja sebanyak RM101-700/sebulan sahaja untuk keperluan asasi. Mereka ini berada di dalam kategori miskin tegar. Kalau kita gandingkan maklumat dalam Jadual 2 (mengenai pendapatan bulanan isi rumah) dan Jadual 4 ini, bolehlah kita simpulkan bahawa isi rumah kajian yang menerima BKK menghabiskan hampir semua pendapatan bulanan mereka untuk tujuan perbelanjaan keperluan asasi. Mereka langsung tidak mampu untuk menyimpan atau menabung sedikit pendapatan mereka untuk kegunaan masa hadapan.

Kajian ini juga mendapati bahawa perbelanjaan bulanan isi rumah mempunyai hubungan yang signifikan dengan peluang pemohon menerima atau tidak menerima bantuan kewangan awam. Dapatan ini membuktikan bahawa selain daripada pendapatan bulanan isi rumah, perbelanjaan bulanan isi rumah untuk keperluan asasi juga boleh digunakan sebagai kayu pengukur untuk menilai keupayaan ekonomi sesebuah isi rumah, dan seterusnya boleh digunakan sebagai indikator dalam memutuskan sama ada sesebuah isi rumah itu layak diberi bantuan sosial awam atau sebaliknya.

\section{PERBINCANGAN}

Kajian ini dengan jelasnya menunjukkan yang ujian kelayakan berasaskan pendapatan masih relevan digunakan bagi memilih dan "menapis" pemohon yang benar-benar layak diberi bantuan. Indikator-indikatornya yang kesemuanya bersifat "boleh dan/atau mudah diukur; iaitu diukur dengan menggunakan nilai wang nampaknya mudah digunakan. Namun begitu, terdapat beberapa aspek dalam indikator ekonominya yang perlu diberi perhatian serius. Namun begitu, dalam bahagian ini kami hanya menyentuh aspek fragmentasi atribut-atribut ekonomi yang digunakan di dalam menilai keupayaan ekonomi isirumah dan integrasi beberapa atribut sosial ke dalam peraturan kelayakan berasas pendapatan. 


\section{Fragmentasi atribut ekonomi yang digunakan di dalam menilai keupayaan ekonomi isirumah}

Indikator paras garis kemiskinan (PGK) yang digunakan sebagai asas kelayakan memang nampak relevan dalam mengelompokkan pendapatan individu kepada miskin dan miskin tegar; mahupun miskin relatif. Limitasi indikator ini yang boleh menyebabkannya "mengeluarkan" pemohon yang layak daripada layak diberi bantuan adalah kemampuan indeks ini untuk bertindakbalas secara automatik dengan inflasi ekonomi. Keanjalan indeks ini untuk berubah mengikut inflasi penting bagi memastikan nilai PGK sentiasa dapat menyesuaikan nilainya dengan kadar inflasi. Perkara ini perlu diberi perhatian khusus kerana nilai PGK tidak sering berubah; sedangkan kadar inflasi berubah secara mendadak. Nilai PGK yang sama digunakan selama beberapa tahun walaupun harga barangan keperluan asasi sentiasa berubah di sepanjang masa. Begitu juga, harga barangan pengguna selalunya naik secara mendadak; berbanding dengan tahap upah/gaji yang naik secara malar selepas beberapa tahun bekerja. Nilai kewangan PGK yang tidak bersifat "inflation-proof" boleh menyebabkan ukuran kelayakan berasas pendapatan yang digunakan kurang dan/atau tidak tepat.

Berbalik semula kepada penggunaan terma "miskin" dan "miskin tegar" sebagai komponen indikator utama PGK, kami juga mengusulkan agar kedua-dua terma ini diteliti semula secara terperinci. Ini kerana terdapat perbezaan yang begitu jelas di antara kekurangan keperluan yang dialami oleh sesebuah isirumah yang miskin dan isirumah yang mengalami miskin tegar. Kelayakan bagi isirumah dari kedua-dua kategori miskin ini menerima bantuan sosial awam perlu dibezakan juga. Ini kerana apabila BKK menjadikan syarat kanak-kanak miskin layak memohon bantuan ini, tetapi kanak-kanak yang berada dalam kategori miskin tegar lebih berpeluang diberi bantuan, sudah pasti ini menyebabkan peluang kanak-kanak miskin; berbanding miskin tegar, untuk mendapat bantuan tipis. Kegagalan pihak pentadbir BKK mengasingkan pemohon dari isirumah miskin dan miskin tegar menyebabkan wujudnya lebih ramai (over representation) kanakkanak miskin tegar; sedangkan bilangan kanak-kanak yang miskin yang juga layak diberi bantuan kurang (under representation). Mungkin ada baiknya kalau dua skim BKK yang berlainan diwujudkan; iaitu satu skim spesifik untuk kanak-kanak dari isirumah miskin tegar dan satu skim lagi khusus untuk kanak-kanak dari isirumah miskin.

Satu perkara yang agak menonjol berkaitan dengan penggunaan indikator PGK ini adalah indikator ini kurang memberi tumpuan kepada penggunaan terma keperluan secara menyeluruh. Bantuan sosial awam 
diwujudkan untuk memenuhi defisit keperluan masyarakat. Maka itu, terma "keperluan" perlu diteliti secara mendalam dan diintegrasi ke dalam pembinaan indikator PGK. Indeks PGK sedia ada gagal untuk mengambil kira terma keperluan yang dirasakan (felt need) oleh kumpulan sasar sesebuah bantuan sosial. Bradshaw (1972) mengatakan fungsi utama kebajikan sosial adalah untuk bertindakbalas dan memenuhi keperluan anggota masyarakat. Justeru itu, konsep "keperluan" tidak boleh diambil mudah atau diperlekehkan.

"Keperluan" seharusnya satu perkara yang bersifat objektif dan boleh diukur kuantitinya. Bradshaw (1972) juga mengatakan yang terma keperluan dibina oleh masyarakat yang memerlukan atau mengalaminya. Cara sesebuah kumpulan atau komuniti sosial mempersepsikan atau menyatakan keperluan mereka perlu diberi perhatian khusus. Menerusi taksonomi keperluan manusia Bradshaw, keperluan manusia boleh dinilai menerusi empat cara; iaitu menerusi keperluan normatif, keperluan komparatif/relatif, keperluan yang dirasakan (felt need) dan keperluan yang dinyatakan oleh individu (expressed need). Indikator PGK sedia ada lebih cenderung memberi tumpuan kepada keperluan normatif dan keperluan komparatif/relatif. Terma keperluan yang dirasakan (felt need); iaitu "...what a person or a group believe they need" (Baldock et al., 1999) dan keperluan yang dinyatakan oleh individu (expressed need); iaitu perubahan keperluan yang dirasakan berlaku tidak diambil kira dalam pengiraan PGK. Keperluan yang dirasakan oleh individu perlu diberi perhatian dalam penilaian permohonan kerana setiap individu mempunyai keperluan yang berbeza. Apa yang disediakan oleh pengeluar perkhidmatan mungkin tidak sesuai dengan keperluan individu ini. Keperluan yang dirasakan memerlukan pelaksana melakukan prosedur penilaian keperluan dalam memilih pemohon yang benar-benar sesuai dengan bantuan yang ada.

Begitu juga, kebanyakan keperluan yang dinyatakan oleh pengguna (expressed need) lazimnya merujuk kepada keperluan-keperluan sosial baru yang terbit daripada perubahan sosial yang berlaku. Perkara ini penting diberi perhatian kerana pihak pengeluar bantuan boleh menggunakan indeks ini bagi memastikan jenis bantuan yang diberikan masih sesuai lagi dengan keperluan sosial baru. Barangan dan perkhidmatan yang menjadi keperluan hidup dalam alaf ini perlu diambil kira. Televisyen, telefon dan kenderaan umpamanya tidak boleh lagi dilihat sebagai barangan mewah sehingga menyebabkan isirumah yang memilikinya tidak layak dipertimbangkan untuk diberi bantuan. Ini kerana barangan tersebut telah menjadi barangan keperluan hidup pada kehidupan moden hari ini. Aspek ini juga perlu diteliti dengan mendalam oleh pihak yang menilai kelayakan pemohon bantuan. 
Aspek terakhir berkaitan penggunaan atribut ekonomi dalam ukuran peraturan kelayakan berasas pendapatan yang ingin disentuh dalam bahagian ini adalah berkaitan dengan kegagalannya mengambil-pakai dengan jelas beberapa pengiraan alternatif status pendapatan sesebuah isirumah. Contoh yang paling ketara adalah penggunaan atribut perbelanjaan bulanan isirumah. Ini merupakan alternatif yang relevan dan rasional bagi menilai kekuatan ekonomi sesebuah isirumah. Selain daripada perbelanjaan bulanan bagi pembelian keperluan asasi seperti barang makanan dan bayaran utiliti asas, perbelanjaan bulanan keluarga juga perlu diperluaskan lagi rangkumannya agar meliputi perbelanjaan untuk pendidikan/persekolahan anak, kos rawatan perubatan dan kesihatan anggota isirumah yang berpenyakit kronik dan uzur, bayaran komitmen tetap bulanan seperti bayaran pinjaman pembelian rumah, sewa rumah, pembayaran ansuran bulanan kereta, bayaran pinjaman peribadi dan sebagainya.

\section{Integrasi beberapa atribut sosial ke dalam peraturan kelayakan berasas pendapatan}

Kelemahan ketara penggunaan peraturan kelayakan berasas pendapatan adalah ia terlalu memfokus kepada sumber pendapatan dan perbelanjaan isi rumah sahaja. Masih terdapat indikator lain yang sepatutnya diambil-kira dalam menjelaskan tentang kemiskinan sesebuah isi rumah. Pendek kata, semua atribut sosial di atas perlu diambilkira dalam menilai dan memilih pemohon yang layak diberi bantuan. Tindakan mengambilkira atribut-atribut berkenaan atau tindakan mengintegrasi atribut-atribut berkenaan dengan peraturan kelayakan berasaskan pendapatan mampu membentuk satu garis panduan pemilihan penerima bantuan yang lebih komprehensif.

Selain itu, kami juga mengusulkan agar ukuran kelayakan berasaskan pendapatan mengambil kira beberapa indikator sosial yang bersifat intangible dalam indikator-indikator kelayakannya. Ini kerana terdapat beberapa indikator sosial seperti keadaan kesihatan anggota isirumah, hubungan pemohon dengan aktor politik yang mempengaruhi proses penyampaian bantuan, akses pemohon terhadap maklumat bantuan, kuasa budibicara pegawai yang mentadbir dan menilai kelayakan pemohon dan sistem pentadbiran bantuan itu sendiri yang mempunyai pengaruh kuat ke atas potensi individu memohon dan memperoleh bantuan. Alexandrova dan Grishina (2007) mendapati indikator-indikator sosial berkenaan mempunyai pengaruh yang sama kuat dengan indikator-indikator ekonomi yang digunakan dalam ukuran kelayakan berasas pendapatan dalam mempengaruhi potensi pemohon bantuan menerima bantuan sosial awam 
yang dipohon. Mereka merujuk indikator-indikator sosial berkenaan sebagai indikator-indikator luaran yang berisiko untuk meletakkan sesebuah keluarga dalam kemiskinan dan indikator-indikator risiko yang menyebabkan isirumah yang berkeperluan dan layak diberi bantuan tercicir daripada proses saringan pemilihan pemberian bantuan.

Kami ingin memetik angkubah kesihatan sebagai contoh. Alexandria dan Grishina (2007) telah menggunakan elemen status kesihatan anggota isirumah sebagai salah satu indikator peraturan kelayakan dalam pemberian bantuan kewangan kepada kanak-kanak miskin di Rusia. Mereka mendapati bahawa kanak-kanak yang datang dari isirumah yang ketuanya sakit lebih berpeluang diberi bantuan; berbanding daripada pemohon yang ketua isirumahnya sihat. Ini kerana dalam beberapa siri kajian mereka mengenai aspek ini menunjukkan rata-rata isi rumah yang miskin diketuai oleh ibu atau bapa atau penjaga yang mengalami pelbagai jenis penyakit yang kritikal, seperti kencing manis, darah tinggi, buasir, tuberkulosis, asma, sawan dan strok. Ketua isirumah yang berpenyakit ini memberi impak yang besar kepada kewangan isi rumah mereka kerana lazimnya mereka tidak berupaya untuk bekerja atau terlibat dalam pekerjaan yang lasak atau berat.

Selain daripada ketua isirumah, status kesihatan tanggungan isirumah juga berperanan penting dalam mempengaruhi perbelanjaan bulanan isirumah. Sekiranya isi rumah perlu membiayai rawatan ahli keluarga yang sakit, ini juga akan membebani keadaan keluarga mereka. Contohnya jika nenek atau datuk yang sakit akan menjejaskan kewangan isi rumah, kerana perbelanjaan untuk perubatan meningkat. Fenomena sebegini akan menambahkan tekanan kewangan bagi isi rumah kanak-kanak yang miskin. Alexandria dan Grishina (2007) dalam kajian mereka juga mendapati bahawa status kesihatan anggota isirumah mempunyai hubungan yang signifikan $(p \leq 000)$ dengan peluang pemohon menerima bantuan sosial awam. Dari segi frekuensi, mereka mendapati kebanyakan kanak-kanak yang diberi bantuan kewangan awam di Rusia serta di beberapa negara Eropah datang dari isirumah yang mempunyai tanggungan anggota isirumah yang berusia dan uzur, yang memerlukan rawatan dan perubatan kesihatan yang tetap pada setiap bulan, serta kanak-kanak yang isirumahnya ada mempunyai anggota yang berpenyakit kronik.

Atribut sosial lain yang juga berpengaruh dalam mempengaruhi peluang pemohon menerima bantuan sosial awam adalah tindakan pelabelan atau memberi stigma negatif kepada pemohon dan penerima bantuan sosial awam. Impak pelabelan/stigma ini merujuk kepada kesan yang bakal dihadapi oleh isirumah pemohon sekiranya pemohon memohon/mendapat 
bantuan. Stigma sering kali dikaitkan dengan kehilangan rasa hormat dan maruah diri, rasa bersalah, malu daripada kesalahan atau kegagalan peribadi (David, 1977). Goffman (1970) menyifatkan individu tersebut sebagai individu yang beridentiti tercemar (spoiled identity). Penerima bantuan sosial awam selalunya dikaitkan dengan label pemalas, tidak tahu berdikari, suka bergantung pada orang lain, individu yang tidak tahu malu dan sebagainya (Spicker, 1984; Titmuss, 1962). Stigma meninggalkan kesan positif atau negatif kepada individu (Alexandrova dan Grishina, 2007; Van Oorscho, 1996; Moffitt, 1983). Hal ini menyebabkan ada segelintir individu yang sememangnya layak memohon dan menerima bantuan sosial awam tidak mahu menampil diri memohon bantuan (Alexandrova dan Grishina, 2007; Edmonds, 2005).

Satu lagi atribut sosial yang juga mempunyai pengaruh besar dalam menentukan peluang individu mendapat bantuan adalah hubungan isirumah dengan aktor politik. Ahli politik merupakan golongan yang berpengaruh dalam masyarakat. Mereka cenderung untuk mengawal proses penyampaian bantuan kepada masyarakat. Morris (2008) menjelaskan ahli politik lebih berpengaruh dalam penyampaian bantuan sosial awam; berbanding personel yang mengurus bantuan. Secara tidak langsung, isirumah yang ada hubungan baik dengan aktor politik setempat lebih berpeluang tinggi untuk diberi bantuan sosial; berbanding mereka yang tidak mempunyai hubungan baik dengan faktor politik setempat. Walaupun senario sebegini dilihat sebagai tidak profesional dan tidak adil, amalan ini memang berlaku.

Satu lagi atribut sosial yang mempunyai pengaruh agak signifikan dalam menentukan peluang individu mendapat bantuan adalah akses isirumah terhadap maklumat mengenai bantuan. Di United Kingdom contohnya, sistem kebajikan sosial awamnya telah mendapati yang aksesibiliti klien perkhidmatan terhadap maklumat mengenai perkhidmatanperkhidmatan dan program-program sosial awamnya merupakan faktor utama kepada keberkesanan proses penyampaian dan proses penerimaan bantuan-bantuan sosial awam di negara tersebut semenjak dari peringkat awal pembentukan Negara Kebajikannya (Spicker, 1998). Menekankan kepentingan aksesibiliti klien kepada maklumat bantuan/program, Laporan Seebohm 1968 contohnya dengan jelasnya mendesak agar setiap agensi perkhidmatan manusia/sosial di negara berkenaan membangunkan sistem maklumat program/bantuan/perkhidmatan yang mudah diakses oleh semua anggota masyarakat di negara tersebut. Antara maklumat asas yang perlu ada di dalam sistem maklumat bantuan/perkhidmatan sosial di setiap pelosok negara tersebut adalah lokasi pejabat bantuan bagi memudahkan pemohon bantuan mencari pejabat kebajikan atau pejabat yang menguruskan bantuan, 
informasi mengenai jenis-jenis bantuan sosial yang disediakan, syarat kelayakan bantuan, prosedur memohon memohon bantuan, saluran yang digunakan oleh agensi bagi proses memohon bantuan, perkhidmatan pertanyaan atau inkuiri berkaitan bantuan yang mudah diakses oleh sesiapa sahaja; iaitu samada melalui perkhidmatan telefon atau kaunter yang meletakkan beberapa personel yang berpengalaman di kaunter pertanyaan agensi kebajikan yang mengurus bantuan (Mckay et al., 1977).

\section{PENUTUP}

Secara keseluruhannya, bolehlah kita simpulkan yang peraturan kelayakan berasas pendapatan masih relevan digunakan bagi menapis dan memilih individu yang benar-benar layak diberi bantuan. Atribut-atribut ekonominya yang cenderung terfokus kepada nilai wang memudahkan status ekonomi seseorang individu diukur. Namun begitu, atribut-atribut ekonomi tersebut masih mempunyai beberapa limitasi yang mampu menyebabkan indikatorindikator yang digunakannya bagi mengukur dan menilai kekukuhan ekonomi individu atau sesebuah isirumah kurang tepat. Limitasi-limitasi tersebut sekiranya tidak ditangani dengan cermat boleh menyebabkan segelintir pemohon bantuan yang benar-benar berkeperluan dan berkelayakan menerima bantuan sosial awam tidak diberi bantuan.

Dalam masa yang sama, ia juga boleh menjadi punca kepada keadaan di mana segelintir pemohon yang tidak layak diberi bantuan terpilih untuk diberi bantuan. Bagi mewujudkan sebuah sistem peraturan kelayakan yang adil, sebuah sistem peraturan kelayakan yang bersifat inklusif; iaitu mengintegrasi beberapa atribut ekonomi dengan atribut sosial yang berisiko mempengaruhi tahap pendapatan individu atau isirumah perlu dipertimbangkan. Ini merupakan cabaran kepada para personel dan agensi yang mentadbir-urus bantuan sosial awam kerana ini bukan satu tugas yang mudah. Walau apa pun cabarannya, agensi pengeluar bantuan dan para personel yang mengurus bantuan perlu sentiasa ingat bahawa peraturan kelayakan yang baik mampu membantu kerajaan menyampai bantuan sosial awam kepada kumpulan sasar yang layak secara tepat dan telus. Ia mampu membantu isi rumah dan/atau keluarga serta kanak-kanak miskin keluar dari kemiskinan yang dialami dan seterusnya menikmati kesejahteraan hidup yang sempurna. 


\section{RUJUKAN}

Alexandrova, A. \& Grishina, E. (2007). Who receives targeted benefits in transition? The effect of household characteristic on take-up rates in Russia's Child Allowance Programme. United Kingdom: Cambridge University Press.

Baldock, J., Manning, N., Miller, S. \& Vickerstaff, S. (1999). Social Policy. London: Oxford University Press.

Bradshaw, J. (1972). The concept of social need. New Society. 496:640-643.

Chambers, D.E. (2000). Analysis of eligiblility rules (Who gets what, how much and under what conditions). Social Policy and Social Program. A Method for The Practical Public Policy Analyst. Boston: Allyn and Bacon. Hal. 131-162.

David, A.R. (1977). Richard Titmuss: Welfare and society. London: Heinemann.

Dewan Bahasa dan Pustaka. (2005). Kamus Dewan Edisi Ke-Empat. Kuala Lumpur: Dewan Bahasa dan Pustaka.

Edmonds, E.V. (2005). Targeting Child Benefits in a transition economy. London: University College London.

Friedman, M. (1957). A theory of the consumption function. A study by the National Bureau of Economic Research. New York: Princeton University Press.

Gilbert, N., \& Specht, H. (1974). The basic of social allocations. Dimensions of social welfare policy. New Jersey: Englewood Cliffs. Hal. 54-80.

Gilbert, N., \& Terrell, P. (1998). The Basis of Social Allocations. Dimensions of Social Welfare Policy. Boston: Allyn and Bacon. Hal. 83-115.

Goffman, E. (1970). Stigma: Notes on the management of spoiled identity. Harmondsworth: Penguin Books.

Johnson, M.B. (1971). Household behaviour: consumption, income and wealth. Harmondsworth: Penguin.

Mckay, A., Goldberg, E. M., \& Fruin, D. J. (1977). Consumers and a Social Services Department. London: Routledge \& Kegan Paul Ltd.

Moffitt, R. (1983). An economic model of welfare stigma. The Economic Review. 73(5):1023-1055.

Mohamed Zaini Omar. (2010). Pembasmian kemiskinan di Malaysia. Pengalaman Amanah Ikhtiar. Pulau Pinang: Universiti Sains Malaysia.

Morris, K. (2008). Social Work and multi-Agencies working: Making a difference. Great Britain: The Policy Press. 
Pecora, P.J., Whittaker, J.K., Maluccio, A.N., Barth, R . P., \& Plotnick, R. D. (2000). The children welfare challenge: Policy, practice and research. New York: Aldine De Gruyter.

Siti Hajar Abu Bakar Ah. (2007). Strategi Kebajikan dan Dasar Sosial di Malaysia. Kuala Lumpur: Universiti Malaya. .(2006). Kebajikan sosial: Aplikasi dalam perkhidmatan manusia. Kuala Lumpur: Universiti Malaya.

Spicker, P. (1998). Social policy. Themes and approaches. London: Prentice Hall.

Press.

Thompson, L.H. (1995). The advantages and disadvantages of different social welfare strategies. International Social Security Review.48(34):59-73.

Titmuss. R. (1962). Income distribution and social change: A study in criticism. London: George Allen \& Unwin Ltd.

Towndsend. P. (1975). The scope and limitations of means-tested social service in Britain. Great Britain: Penguin Books Ltd.

Van oorschot, W. (1996). New perspectives on the non-take-up of social security benefits. Tilburg: Tilburg University Press. 